\title{
A Two Slotted Circular Microwave Antenna Design for Hyperthermia System Applicators
}

\author{
Minu Sethi \\ Ph.D. Scholar Faculty of \\ Engineering and Technology \\ Manav Rachna International University \\ Faridabad, 121003, India
}

\author{
Geeta Nijhawan \\ Associate Professoraculty of \\ Engineering and Technology \\ Manav Rachna International University \\ Faridabad, 12003, India
}

\begin{abstract}
The critical element in the hyperthermia system is an antenna. The quality of the system and performance of antenna determines the electromagnetic energy (EM) deposition into the tissue. This paper presents the design and simulation of two slotted circular microwave based antenna used for hyperthermia applicator. The antenna is designed to operate at a frequency of $2.45 \mathrm{GHz}$ which is a designated medical band frequency to be used for hyperthermia applicators. The performance of the two slotted circular microwave antenna is compared with conventional circular microwave antenna. The result shows that slotted antenna offers better gain, high directivity, improved VSWR and an excellent return loss. The design of the proposed two slotted antenna can be used as a single antenna element in future for cancer specific deep region hyperthermia system.
\end{abstract}

\section{Keywords}

Hyperthermia, slotted circular antenna, directivity, gain, VSWR, return loss.

\section{INTRODUCTION}

Cancer is a group of diseases which is characterized by an uncontrolled growth and spread of abnormal cells. According to the facts and statistics given by American cancer society in 2015 , the estimated new cancer cases diagnosed is $1,658,370$ and the death due to cancer is 589,930 [1]. Cancer is one of the leading cause of death and the death rate are expected to continue rising with an estimation of 12 million worldwide in 2030 [2].The combination of hyperthermia with engineering proves one of the best cancer treatment option [3]. A medical treatment for cancer called hyperthermia is a thermal process in which temperature of body tissue is increased between $40 \mathrm{oC}$ and $44 \mathrm{oC}$. To heat superficial tumors many techniques have been proposed for noninvasive hyperthermia applicators [4-5]. For the better penetration of energy to deep located tumors low frequencies are utilized and for confinement of energy with high motion high frequencies are utilized [6].

Either with direct contact or in proximity to patients, applicators using electromagnetic heating are the main component in hyperthermia system and is a determining factor for effective and safe treatment [7]. The EM energy deposition into the tissue is determined by an antenna which elevates the temperature to approximately $40-44 \mathrm{oC}$ that results in direct killing of tumorous cells, stimulation of immune system, enhanced metabolic activity and an improved intake of drug [8]. Micro strip patch antenna is a promising candidate that can be effectively used at microwave frequency to be used in hyperthermia system. It consists of dielectric substrate with a ground plane on the other side [9]. It offers many advantages like low weight, low fabrication cost, less return loss and high directivity [10]. The position and length of the micro strip feeding also shows a drastic change in result [11].

The main goal of the paper is to design and simulate the performance of two slotted circular microwave patch antenna which is operated at frequency of $2.45 \mathrm{GHz}$. The performance of the design is compared with conventional circular microwave patch antenna of same dimensions. The next section gives the design of circular patch microwave antenna and two slotted circular microwave based patch antenna. Section 3 gives the analysis of two designs which are done on IE3D software. The results are shown in section 4 and the last section gives the conclusion.

\section{DESIGN OF CIRCULAR PATCH MICROWAVE ANTENNA}

The design of the proposed antenna is circular in shape. The theoretical calculation and analysis of parameters [12-14] are done using equations (1-3). The actual radius of circular microwave patch antenna with and without slot is given by equation (1)

$$
a=\frac{F}{\sqrt{1+\frac{2 h}{f \pi \epsilon_{r}}\left[\ln \left(\frac{\pi f}{2 h}\right)+1.7726\right]}}
$$

where

$$
F=\frac{8.791 * 10^{9}}{f_{r} \sqrt{\epsilon_{r}}}
$$

The effective radius of antenna is given by equation (3)

$$
a_{e}=a \sqrt{1+\frac{2 h}{\pi a}\left[\ln \left(\frac{a}{2 h}\right)+1.7726\right]}
$$

Where $\mathrm{f}_{\mathrm{r}}$ is the operating frequency of antenna

$\mathrm{a}$ is actual radius of patch

$\mathrm{a}_{\mathrm{e}}$ is effective patch radius

$\mathrm{h}$ is thickness of substrate

$\epsilon_{\mathrm{r}}$ is dielectric permittivity of substrate

The parameter values used in designing are given below:

$\mathrm{f}_{\mathrm{r}}=2.45 \mathrm{GHZ}$

The material used as substrate is $\mathrm{FR}_{4}$ having thickness $\mathrm{h}=$ $1.57 \mathrm{~mm}$ 
Dielectric constant $\epsilon_{\mathrm{r}}=4.4$

$\tan \delta=0.02$

Radius (a) $=16.9 \mathrm{~mm}$

Effective radius $\left(\mathrm{a}_{\mathrm{e}}\right)=17.41 \mathrm{~mm}$

Two rectangular slots 1 and 2 of equal dimensions are cut in both the sides of circular patch as shown in Fig.8 with dimensions

Length $\mathrm{L}_{\mathrm{S} 1}=\mathrm{L}_{\mathrm{S} 2}=8 \mathrm{~mm}$

Width $\mathrm{W}_{\mathrm{S} 1}=\mathrm{W}_{\mathrm{S} 2}=10 \mathrm{~mm}$

\section{ANALYSIS OF CONVENTIONAL AND SLOTTED CIRCULAR PATCH MICROWAVE ANTENNA}

The design of conventional and slotted circular microwave patch antenna is shown in Fig.1 and Fig.2. The frequency of operation is $2.45 \mathrm{GHz}$. Micro strip line feeding is used to energize the antenna which is directly applied to feed point 1.The comparison is based on parameters namely return loss, VSWR, radiation pattern and directivity. The Simulation results are shown in figures.

Return loss is a parameter which indicates how well the matching between the transmitter and antenna has taken place. The return loss graph at a frequency of $2.45 \mathrm{GHz}$ gives the value of $-18 \mathrm{~dB}$ for conventional circular antenna as shown in Fig. 3 and $-30 \mathrm{~dB}$ for two slotted circular patch antenna as shown in Fig.9

Fig.4 and Fig.10 shows the VSWR graph verses frequency. The value of VSWR for the two antennas at $2.45 \mathrm{GHz}$ is 2 and 1.4.The results shows that the antenna had an acceptable performance with value less than or equal to 2 . Gain is a measure of the ability of antenna to direct the input power into radiation in a particular direction and is measured at peak radiation intensity. The value of gain for conventional antenna is $0.5 \mathrm{~dB}$ as shown in Fig.5 and for two slotted circular patch antenna is $2 \mathrm{~dB}$ shown in Fig. 11 .

Directivity is the measure of the concentration of radiation in the direction of maximum. The value of directivity for conventional circular antenna is $6.24 \mathrm{~dB}$ as shown in Fig.6 and two slotted circular antenna is $6.36 \mathrm{~dB}$ as shown in Fig.12.

The radiation pattern of an antenna is a plot of the far field radiation properties of an antenna as a function of spatial coordinates which are specified by elevation angle $(\Theta)$ and azimuth angle $(\phi)$. It shows the antenna directivity as well as gain at various points in space. The 3D graph and 2D polar graph for conventional circular patch antenna are shown in Fig. 7 and Fig. 8 and for two slotted circular antenna are shown in Fig. 13 and Fig. 14.

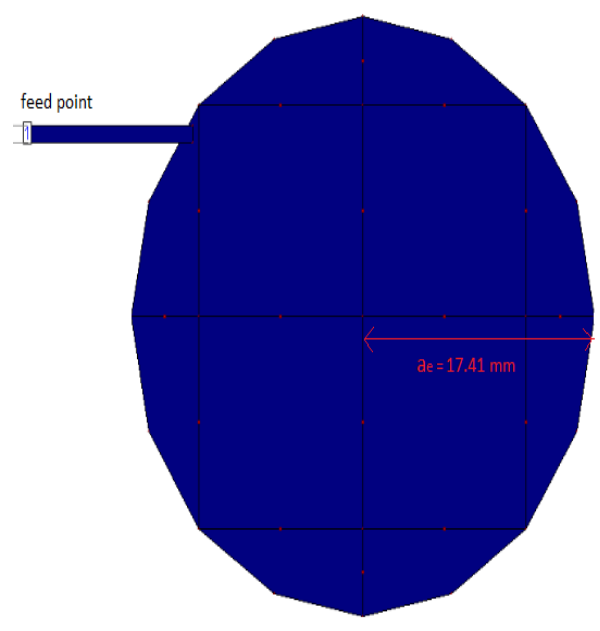

Fig 1. Conventional Circular patch antenna

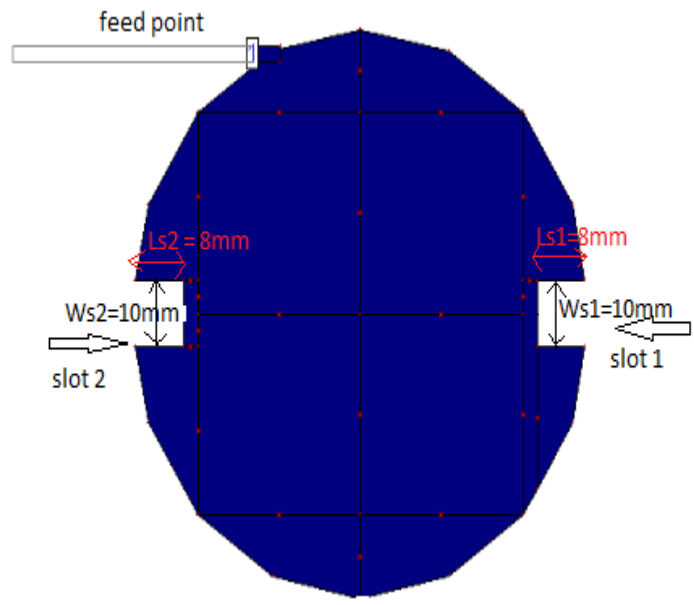

Fig 2. Slotted circular patch antenna

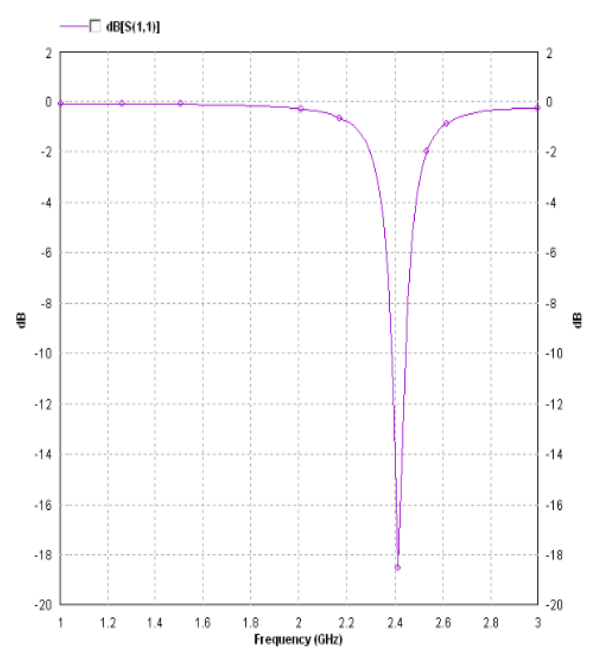

Fig3. Return loss vs frequency graph 


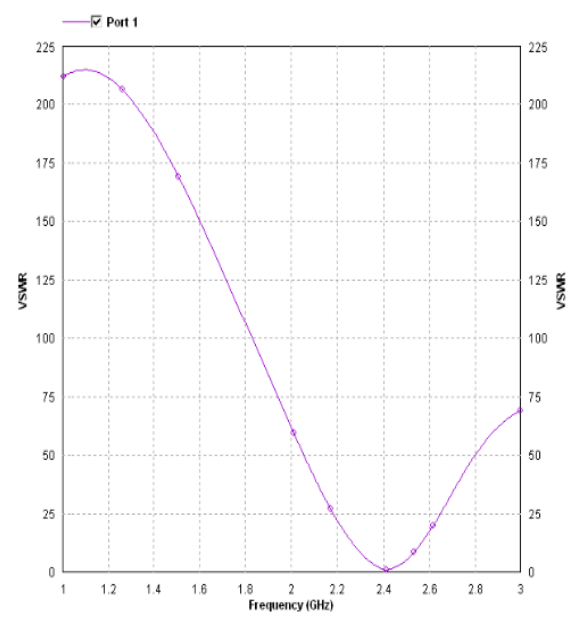

Fig 4. VSWR vs frequency graph

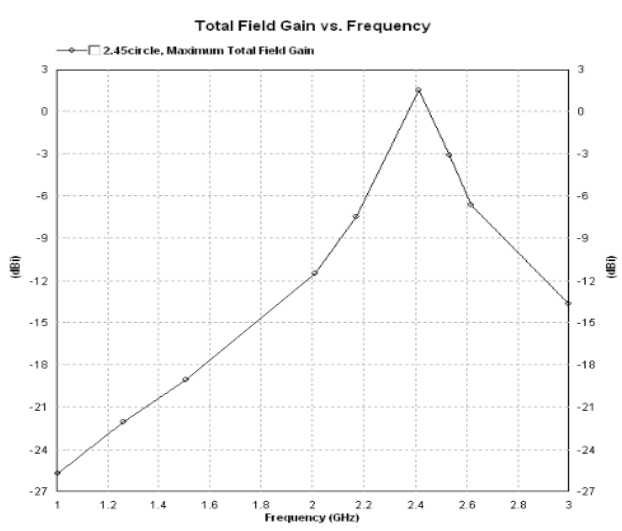

Fig 5. Gain vs frequency graph Total Field Directivity vs. Frequency

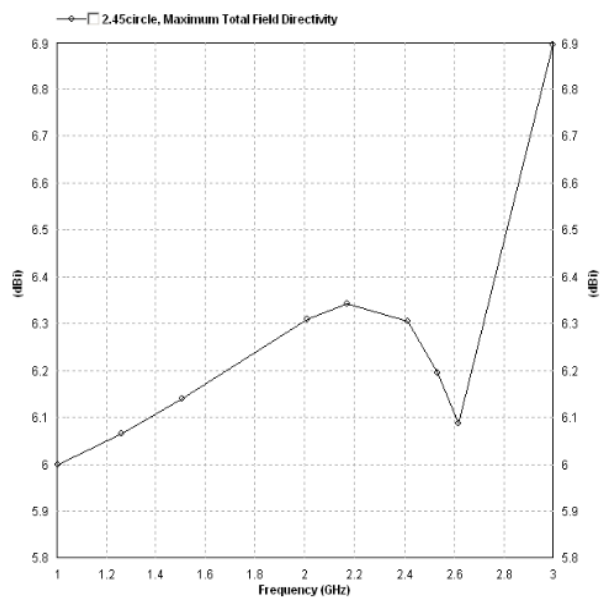

Fig 6. Directivity vs frequency graph

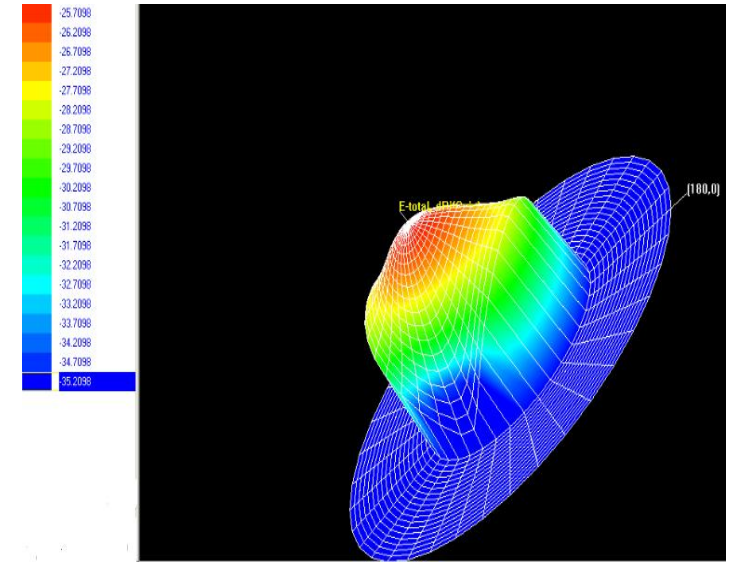

Fig 7. 3D Radiation pattern graph

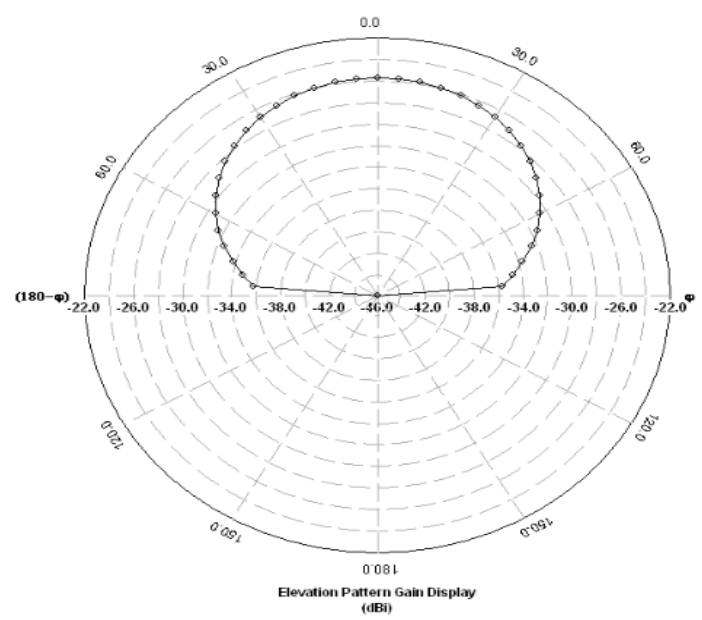

Fig 8. 2D Radiation Pattern graph

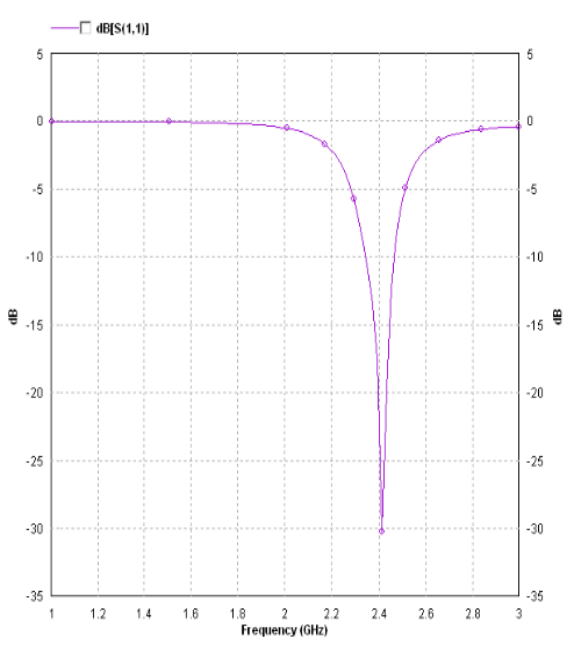

Fig 9. Return loss vs frequency graph 


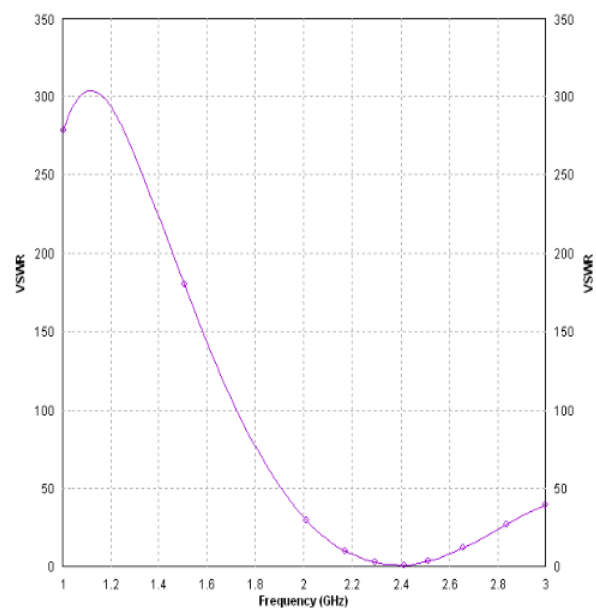

Fig 10. VSWR vs frequency graph

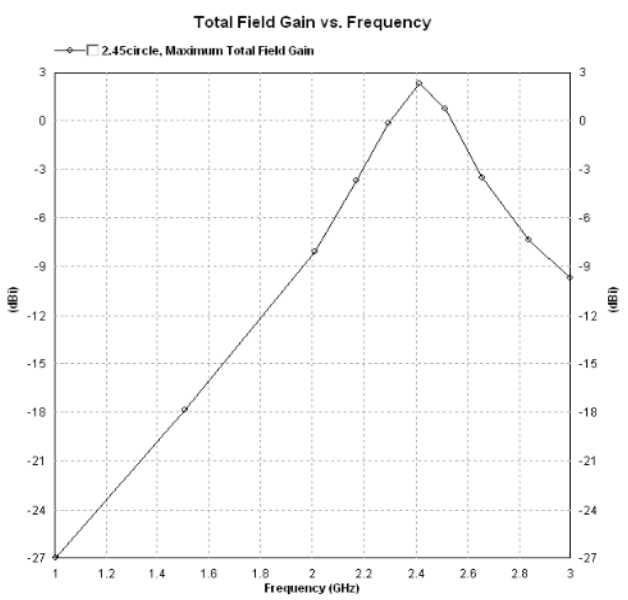

Fig 11 .Gain vs frequency graph

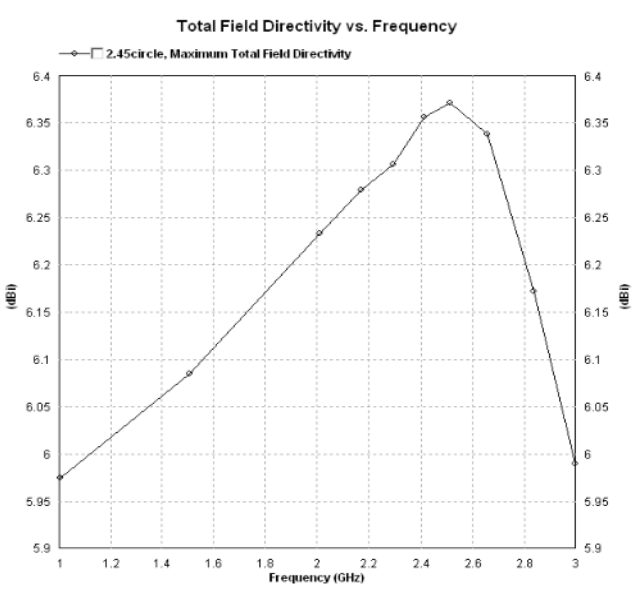

Fig 12. Directivity vs frequency graph

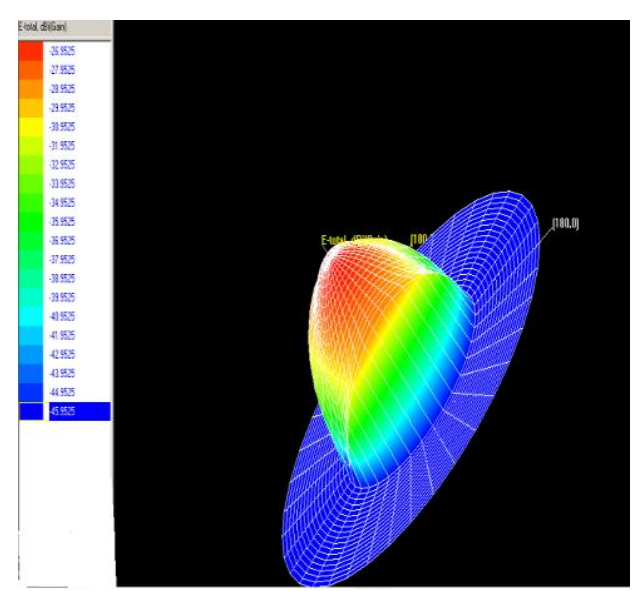

Fig 13. 3D Radiation pattern graph

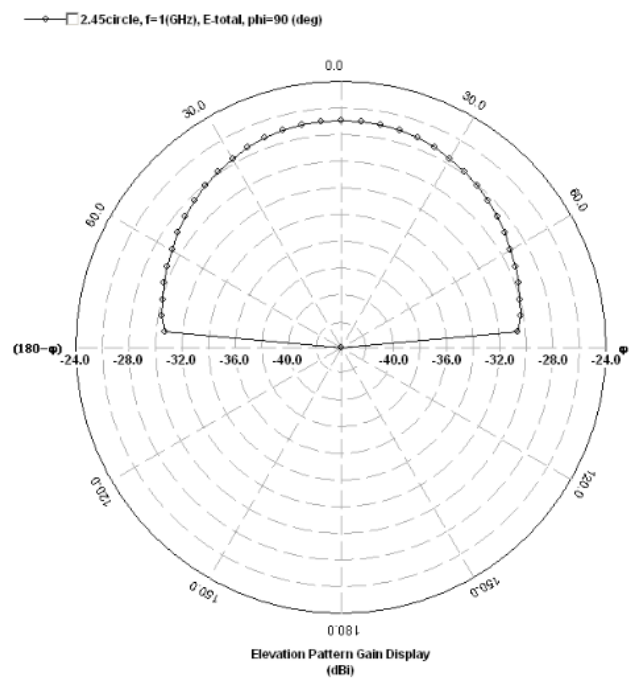

Fig 14. 2D Radiation Pattern graph

\section{RESULTS}

The comparison between conventional and two slotted circular microwave antenna based on different parameters is shown in Table1. Both the antennas are designed for microwave frequency $2.45 \mathrm{GHz}$. The simulation gives better results for two slotted circular antenna which effectively determines the electromagnetic energy deposition in tissues which is necessary to elevate the temperature of cancerous cells.

Table 1: Comparison between conventional and two slotted circular microwave antenna

\begin{tabular}{|c|c|c|c|}
\hline S.NO & Parameters & $\begin{array}{c}\text { Conventional } \\
\text { circular } \\
\text { antenna }\end{array}$ & $\begin{array}{c}\text { Two } \\
\text { slotted } \\
\text { circular } \\
\text { antenna }\end{array}$ \\
\hline 1. & Gain & $0.5 \mathrm{~dB}$ & $2 \mathrm{~dB}$ \\
\hline 2. & Directivity & $6.24 \mathrm{~dB}$ & $6.36 \mathrm{~dB}$ \\
\hline 3. & Return Loss & -18 & -30 \\
\hline 4. & VSWR & 2 & 1.5 \\
\hline
\end{tabular}




\section{CONCLUSION}

In the present research effort is made to design and simulate two slotted circular microwave patch antenna at a frequency of $2.45 \mathrm{GHz}$ and are compared with conventional circular microwave patch antenna. Micro strip line feeding is used to energize the antenna which are directly applied to feeding point 1 . The design of two antennas are simulated on IE3D software which is a method of moment EM simulator which demonstrate that the two slotted circular microwave patch antenna provides a better focus with high directivity and low return loss as compared with conventional circular microwave patch antenna and permit its application in microwave hyperthermia system for cancer treatment.

\section{REFERENCES}

[1] American cancer society (2015). [Online].Available: http: // www.cancer.org/

[2] WHO - World health organization (2015). [Online]. Available: http://www.who.int/en

[3] Sethi M. and Chakarvarti S. K, 2015 Hyperthermia Techniques for cancer treatment: A Review. International Journal of PharmTech Research CODEN (USA): IJPRIF, ISSN: 0974-4304 Vol.8, No.6, pp. 292299.

[4] M.Converse, E.J.Bond, B.D.Veen and S.C.Hagness, 2006.A Computational study of ultra wide band verses narrow band microwave hyperthermia for breast cancer treatment. IEEE Transactions on microwave theory and techniques, Vol-54, pp.2169-2180.

[5] P. F. Maccarini, H.O.Rolfsnes and P. Stauffer, 2004. Optimization of dual concentric conductor antenna for superficial hyperthermia applicators. In preceding of 26th Annual International Conference of IEEE EMBS, San francisco, CA, USA.
[6] A. Kreiner, V.Thater Vento, P. Levinag, J. Bergeron, H. D. Paolo, A.Burlon, J.Kesque, 2009. Development of a tandem electrostatic quadruple accelerator facilities for BNCT", Applied Radiation and isotopes, Vol-67, pp.S266-S269.

[7] C.K.Chou., 1992 Evalution of microwave hyperthermia applicator. Bio electromagnetics Vol-13, pp-581-597.

[8] Van der Zee, 2002. Heating the patient: a promising approach? Annuals of Oncology, Vol. 13, 110. 8, pp. 1173-1184.

[9] J.C. Liberti, 1999. T.S. Rappaport. Smart Antenna for wireless communication. IS-95 and third generation CDMA applicators", prentice hall, New Delhi.

[10] H.F. Abu Tarbush, H.S. Ali-Raweshidy, July 2008. A connected U-shaped and E-shaped dual band patch antenna for different wireless applications. The second international EURASIP workshop on RFID Technology.

[11] Patil V. P, Oct. 2012. Enhancement of bandwidth of rectangular patch antenna using two square slots techniques. International Journal of Engineering Sciences \& Emerging Technologies ISSN: 2231 - 6604. Volume 3, Issue 2, pp.: 1-12 @IJESET

[12] Balanis C. A, 2005 Antenna Theory, Analysis and Design. 3rd ed. Hoboken, NJ: Wiley.

[13] J. R. James and P. S. Hall, 1985. Handbook of micro strip antennas. Peter Peregrinus, London, UK.

[14] D. M. Pozar, and D. H. Schaubert, 1995 Micro strip Antennas, the Analysis and Design of Micro strip Antennas and Arrays. IEEE Press, New York, USA. 